\title{
A simplified design of clamping system and fixtures for friction stir welding of aluminium alloys
}

\author{
Mohammed. M. Hasan ${ }^{1,2^{*}}$, M. Ishak ${ }^{1,3}$ and M.R.M. Rejab ${ }^{1}$ \\ ${ }^{1}$ Faculty of Mechanical Engineering, ${ }^{3}$ Automotive Engineering Centre, \\ Universiti Malaysia Pahang, 26600 Pekan, Pahang, Malaysia \\ Phone: +6094246200; Fax: +6094246222 \\ ${ }^{2}$ University of Technology, Baghdad, Iraq \\ *Email:mhmeam@yahoo.com
}

\begin{abstract}
Sound friction stir welds could be attained by using an active design of backing/clamping system with a proper selection of the welding parameters. This work presented a simplified design of fixtures and backing plates to be used for friction stir welding of aluminum alloys. The test-rig was constructed to prevent dispersal or lifting of the specimens throughout the joining process and to ensure uniform distribution of temperature along the plates. The workpieces were subjected to uniform lateral and vertical pressures by means of bolts and nuts. Compound backing plates and pressure bars with additional side plates were included to increase the heat sink. Several coupons of dissimilar aluminum alloys AA7075 and AA6061 were joined to inspect the validity of this design. The tests showed promising results with defects-free welds, good strength and smooth surface finish without geometric imperfection and gap creation between the welded specimens. Efficiency of the joint reached its maximum value of about $82 \%$ with respect to the ultimate strength of the AA6061 alloy at $1100 \mathrm{rpm}$ rotation speed and 300 $\mathrm{mm} / \mathrm{min}$ feed. These results encourage using and improving the present design for future studies of friction stir welding.
\end{abstract}

Keywords: Aluminum alloys; backing plate; clamping system; friction stir welding.

\section{INTRODUCTION}

In fiction stir welding (FSW), backing plates and fixtures are quite significant factors [13]. It is important that the workpieces should not spread or be lifted during the process; therefore, welding fixtures must be designed with features that are enable to achieve this objective. The quality of welding is dependent on the manufacturing precision of the clamping system and the welding table [4]. Moreover, the impact of clamping process on the joint performance should be recognized so that the required constant quality could be ensured. The method of clamping and its effects on machine processes are well understood. Besides that, clamping claws is an easy and less costly system, however, it leads to varying temperature distributions which could be improved through the use of pressure bars [5-7]. Advanced research have indicated that continuous clamping approaches could lead to a more consistent FSW quality along the joint's length [8]. Essential forces are required in FSW that should be supported by the fixtures, leading to a significant rise in total process costs. Thus, appropriate knowledge regarding the required forces would result in the chances of optimization of clamping system with respect to cost and efficiency [9]. At the time of designing new optimized clamping 
systems for particular applications, there is a need for essential information about the actual forces required so that the parts to be joined in place are held correctly. Little information is available in the literature regarding the impact of clamping systems on the mechanical behavior of the welded joints. Clamping force with simplified clamping conditions for the purpose of fusion and laser welding were studied by a number of researchers [10-16]. Through the investigations, it was observed that increasing the restraining force results in improvement of the welded joints. In FSW, Christner and Sylva [17] recorded that the formation of gap between specimens up to $36 \%$ of the plate thickness does not affect the joint strength. In a similar work, Leonard and Lockyer [18] noted that a gap presence up to $33 \%$ of the workpiece thickness could be tolerated without the existence of weld flaws. On the other hand, Richter and his group of researchers [19] observed that lesser distortion and a more consistent residual stresses distribution through the thickness can be achieved by applying higher clamping forces. It was demonstrated that the possibility of defects could also be minimized by preventing any creation of gaps between the two butt plates, as shown in Figure 1.
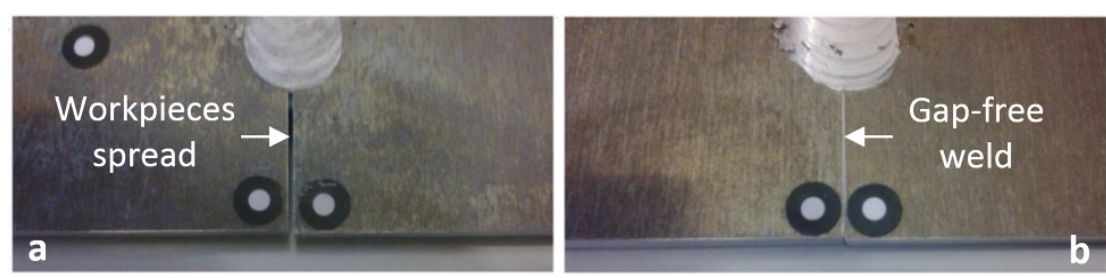

Figure 1. Gap between specimens at the start of the FSW process based on the condition of clamping [19]. (a) without lateral pressure, (b) with lateral pressure.

During the FSW process of higher-temperature alloys, such as steel and titanium, it was found that cooling of the welding tool and anvil is essential to avoid movement of the thermal energy into the machine's spindle. A good design of fixture can lead to dissipating heat away from the workpiece, and hence improving the weld quality and performance [20]. On contrary, cooling is not required for the FSW of lower-temperature aluminum and magnesium alloys. Such alloys are commonly friction stir welded with ambient air-cooled anvil and welding tool [8]. However, material mixing and mechanical properties of the joint can be significantly improved by the use of compound backing plates with different thermal diffusivity [16, 21-25]. This paper aims to accomplish and equip a simplified design of clamping system and fixtures to be used as a FSW test-rig. The validity of this design is verified experimentally by welding some pairs of AA7075AA6061 aluminum alloys and investigating the mechanical properties and microstructure of joints. These two alloys are widely used in the automotive, aircraft, aerospace, marines, and transportation industries [26-29]. Aluminum 7075, along with the traditional welding techniques, is relatively a high strength material that can be used for highly stressed structural parts [30]. The widely available AA6061-T6 has a good workability, high resistance to corrosion, and excellent joining characteristics [31]. For instance, the FSW of these dissimilar alloys fully utilizes both materials [32, 33]. Although the FSW of similar and dissimilar materials has been used in many research studies [34-39], limited interest was found in literature regarding these two series of aluminum alloys [40-44]. In all of these articles, weld temperature, process parameters and the placement of materials on the advancing side (AS) and retreating side (RS) were examined without any referring to the clamping system and fixtures. High and low speeds, in several conditions were applied. Using Taguchi method, parametric optimization was achieved by Shah et al. [43] 
to evaluate the tensile strength of joint under several welding speeds and tool tilt angle. Maximum tensile strength of $219.6 \mathrm{MPa}$ was observed at $1000 \mathrm{rpm}$ and $110 \mathrm{~mm} / \mathrm{min}$ welding speeds and $3^{\circ}$ of tilt angle. Furthermore, Guo et al. [40] reported that high traverse speed can be used to join these two alloys when the softer alloy was placed on the AS, in which joint efficiency reached $79 \%$ with respect to the tensile strength of the AA6061 base material. In another study, Sathari et al. [44] noticed the same behavior when the AA6061 was placed on the AS. They found that the maximum joint strength of $207 \mathrm{MPa}$ was resulted by this configuration. In the work of Cole et al. [42], the AA6061 alloy was also placed on the AS and the welding tool was shifted toward the AA7075 to improve the joint strength. Other than that, the same material position was made by Ipekoglu and Çam [41] to investigate the behavior of AA7075-AA6061 friction stir weldments under different temper conditions and post-weld heat treatment. Consequently, nine pairs of tool rotation and welding speeds were selected in the present work to examine the ability of the self-designed backing/clamping system of producing sound welds with high tensile strength.

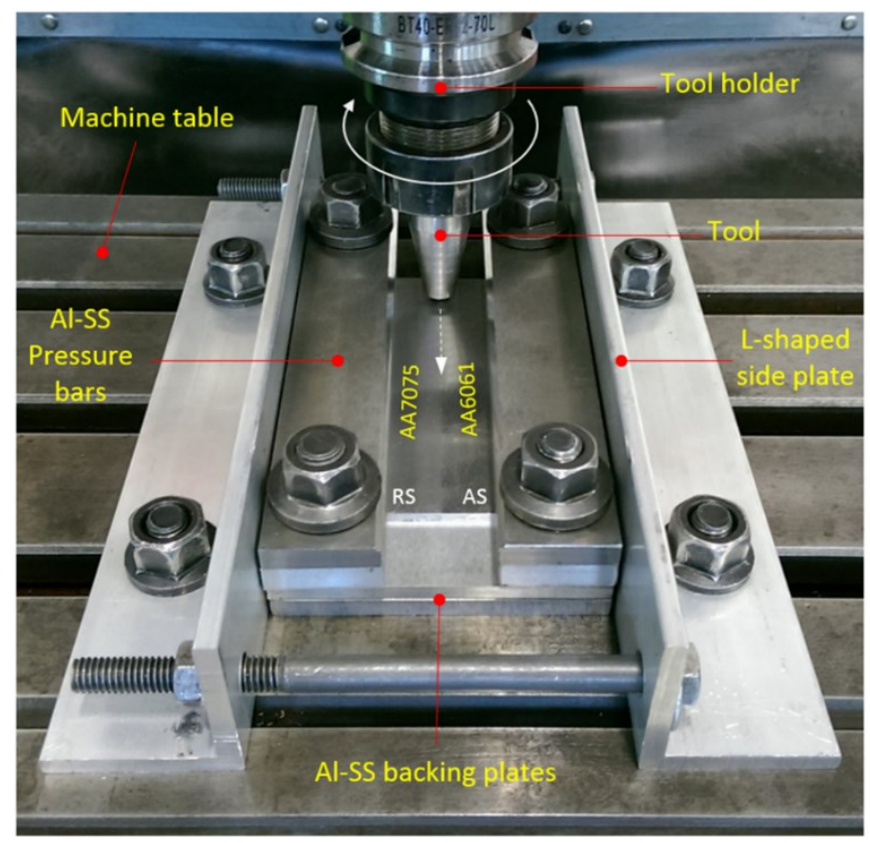

Figure 2. The assembly of the FSW test-rig on the machine's table.

\section{EXPERIMENTAL SET UP}

\section{Test-Rig Characterization}

Figure 2 shows a photo of the simplified FSW testing structure. Length of the backing plates and fixtures is selected to be suitable for the available milling machine table, while the width can be enlarged depending on the dimensions of the welded coupons. The vertical clamping forces are applied by means of pressure bars, bolts, and nuts to ensure uniform pressure and temperature distribution throughout the welded plates [5]. The lateral restraints consist of two L-shaped aluminum plates and two end-screwed bolts. This enables to increase the heat sink [21] and to apply uniform side pressure on the specimens [19]. This side pressure is applied by an easy and economical way, using nuts at the end of the two horizontal bolts. The horizontal plane containing the two specimens is free of bolts and their holes, which aims to avoid any change in the heat sink during the 
process. The design facilitates to use multi-layers of backing plates and pressure bars. Aluminum and stainless steel (Al-SS) compound system is used to increase the cooling rate and hence improving the joint strength [21,22]. Width of the backing plates is slightly less than the total width of the workpiece in order to apply the lateral pressure directly on the workpiece by means of the two L-shaped side plates. This low cost test-rig can be easily handled and it allows controlling the position of the welding tool on the specimens. It is specially designed for butt-joint FSW researches.

\section{Experimental Procedure}

To indicate the effectiveness of the simplified design, dissimilar aluminum AA6061-T6 and AA7075-T6 rolled sheets with dimensions of $125 \times 50 \times 3 \mathrm{~mm}$ were joined in butt configuration by FSW technique. The chemical compositions and physical properties of these two alloys are listed in Tables 1 and 2 respectively. The edges of specimens were ground by an auto-grinding machine and cleaned with acetone and at the same time, a vertical milling machine was used for the FSW process.

Table 1. Chemical composition (wt. \%) of the base materials [45].

\begin{tabular}{cccccccccc}
\hline Material & $\mathrm{Cu}$ & $\mathrm{Mg}$ & $\mathrm{Zn}$ & $\mathrm{Mn}$ & $\mathrm{Si}$ & $\mathrm{Fe}$ & $\mathrm{Cr}$ & $\mathrm{Ti}$ & $\mathrm{Al}$ \\
\hline $7075-$ & $1.2-2$ & $2.1-$ & $5.1-$ & $\mathrm{Max}$ & $\mathrm{Max}$ & $\mathrm{Max}$ & $0.18-$ & $\mathrm{Max}$ & $87.1-$ \\
T6 & & 2.9 & 6.1 & 0.3 & 0.4 & 0.5 & 0.28 & 0.2 & 91.4 \\
$6061-$ & $0.15-$ & $0.8-$ & $\mathrm{Max}$ & $\mathrm{Max}$ & $0.4-$ & $\mathrm{Max}$ & $0.04-$ & $\mathrm{Max}$ & $95.8-$ \\
T6 & 0.4 & 1.2 & 0.25 & 0.15 & 0.8 & 0.7 & 0.35 & 0.15 & 98.6 \\
\hline
\end{tabular}

Table 2. Mechanical properties of the base materials.

\begin{tabular}{ccccc}
\hline Material & $\begin{array}{c}\text { Yield strength* } \\
(\mathrm{MPa})\end{array}$ & $\begin{array}{c}\text { Tensile strength* } \\
(\mathrm{MPa})\end{array}$ & $\begin{array}{c}\text { Vickers } \\
\text { hardness* }\end{array}$ & $\begin{array}{c}\text { Elongation* } \\
(\%)\end{array}$ \\
\hline $7075-\mathrm{T} 6$ & 503 & 571 & 175 & 11 \\
$6061-\mathrm{T} 6$ & 276 & 307 & 107 & 12 \\
\hline
\end{tabular}

* Average values of three tests

Welding line was parallel to the rolling direction of the two sheets. The AA6061 was placed on the AS. A tool made of $\mathrm{H} 13$ steel was used to produce the welding joints $[8,46]$. The shoulder diameter is $12 \mathrm{~mm}$ having an $8^{\circ}$ concave. The pin was tapered with $10^{\circ}$ from $4.2 \mathrm{~mm}$ diameter on the base alongside a length of $2.7 \mathrm{~mm}$. Left-hand threads and single flat were added to the core of the probe to improved the local deformation and material flow [8, 47, 48]. Three distinct tool rotational speed levels of 1000, 1100 and $1200 \mathrm{rpm}$ with three travel velocities of 250,300 and $350 \mathrm{~mm} / \mathrm{min}$ were utilized, as shown in Table 3. The tool tilt angle stayed constant at $3^{\circ}$ from the normal of the workpiece further from the direction of travel. These welding parameters were selected according to a number of preliminary tests based on the literature findings.

The rotating tool pin was gradually inserted between the two sheets until the shoulder could penetrate to about $0.2 \mathrm{~mm}$ inside the workpiece. This generates a frictional heat that is needed to soften the materials around the tool probe. Subsequently, stirring started at a consistent speed along the centerline between the two alloys. After natural aging of about one month since welding, transverse tensile specimens for the welded and base materials are prepared as per the American Society for Testing of Materials (ASTM E8-11) standard. Figure 3 presents the geometry and dimensions of these specimens. 
Tensile tests have been done at room temperature with a speed of $1 \mathrm{~mm} / \mathrm{min}$ using a 50 $\mathrm{kN}$ universal testing machine with bluehill 3 software. Finally, three tensile specimens for each joint were tested, and then the average values of the ultimate tensile strength were noted down.

Table 3. Welding parameters.

\begin{tabular}{ccc}
\hline Specimen & $\begin{array}{c}\text { Rotation speed } \\
(\mathrm{rpm})\end{array}$ & $\begin{array}{c}\text { Welding speed } \\
(\mathrm{mm} / \mathrm{min})\end{array}$ \\
\hline A1 & 1000 & 250 \\
A2 & 1000 & 300 \\
A3 & 1000 & 350 \\
B1 & 1100 & 250 \\
B2 & 1100 & 300 \\
B3 & 1100 & 350 \\
C1 & 1200 & 250 \\
C2 & 1200 & 300 \\
C3 & 1200 & 350 \\
\hline The tool tilt angle stayed constant at $3^{\circ}$ for all cases
\end{tabular}

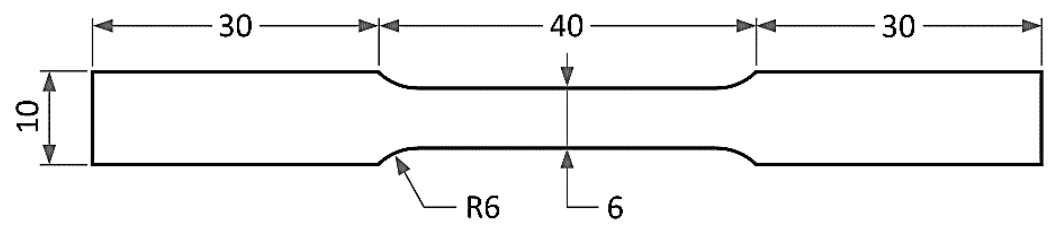

Figure 3. Geometry and dimensions of the tensile specimen in millimeters according to the ASTM E8-11 standard.

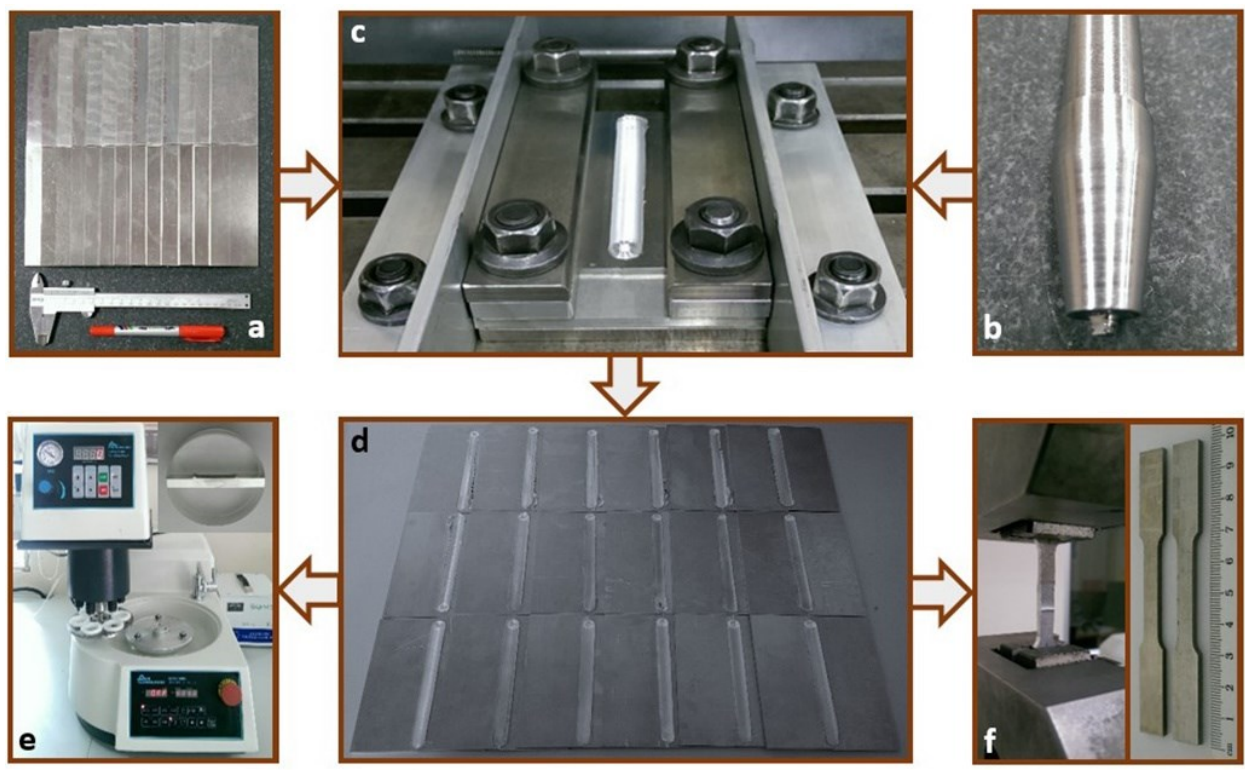

Figure 4. The key stages of the experiment: (a) preparation of the specimens, (b) welding tool, (c) clamping and FSW, (d) welded coupons, (e) grinding and polishing the metallographic specimens, and (f) tensile testing. 
Standard metallographic technique was followed to prepare the metallographic specimens. After complete grinding and polishing using automatic and manual devices, the specimens were etched with a modified Keller's reagent, so that the grain structure of the various weld zones could be observed. The key stages of the experiment are demonstrated in Figure 4. An optical microscope was used to perform the microstructural analysis. An auto Vickers micro-hardness tester was then used to measure the hardness across the mid-thickness of the joint's cross-section in a direction normal to the weld line. The HV0.5 test method was applied with an indent time of 10 seconds.

\section{RESULTS AND DISCUSSION}

Three transverse tensile tests were achieved for each base material (BM) and welded joint and the average values of the ultimate tensile strength (UTS) had been then calculated. Figure 5 presents the average UTS value for each specimen in addition to that of the base alloy (AA6061). The maximum error recorded was less than 5\% and the minimum values were observed near the starting point of welding. The UTS of the AA7075 base alloy was not drawn in this figure, because all specimens failed at the heat affected zone (HAZ) of the AA6061 alloy. Moreover, all of the welded plates exhibited good tensile strength ranging from 220.9 MPa for the (C3) specimen, where the rotation and welding speeds were $1200 \mathrm{rpm}$ and $350 \mathrm{~mm} / \mathrm{min}$ respectively, to the apex of $252.1 \mathrm{MPa}$ when the rotation speed fixed at $1100 \mathrm{rpm}$ and the welding speed at $300 \mathrm{~mm} / \mathrm{min}$ for the (B2) specimen. The highest value of the UTS represents an efficiency of about $82 \%$ with respect to the UTS of the AA6061 alloy. This efficiency is higher than the acceptable limit due to the standards of the American Welding Society (AWS) for FSW [40]. The joint efficiency was calculated with respect to the weaker alloy. For instance, it has been reported in all previous work on dissimilar FSW of alloys and materials, that the maximum tensile strength of the weldment is always less than the weaker material [33]. Due to this, the challenge of joining dissimilar alloys and metals lies in the differences in their chemical and mechanical properties. The differences and gap are relatively high between the selected 7xxx and 2xxx series, as seen in previously in Tables 1 and 2. For that reason, it is hard to achieve very high strength of the welded joints for these two aluminum alloys [34]. However, the calculated efficiency is relatively high compared to the previous published data [40-44].

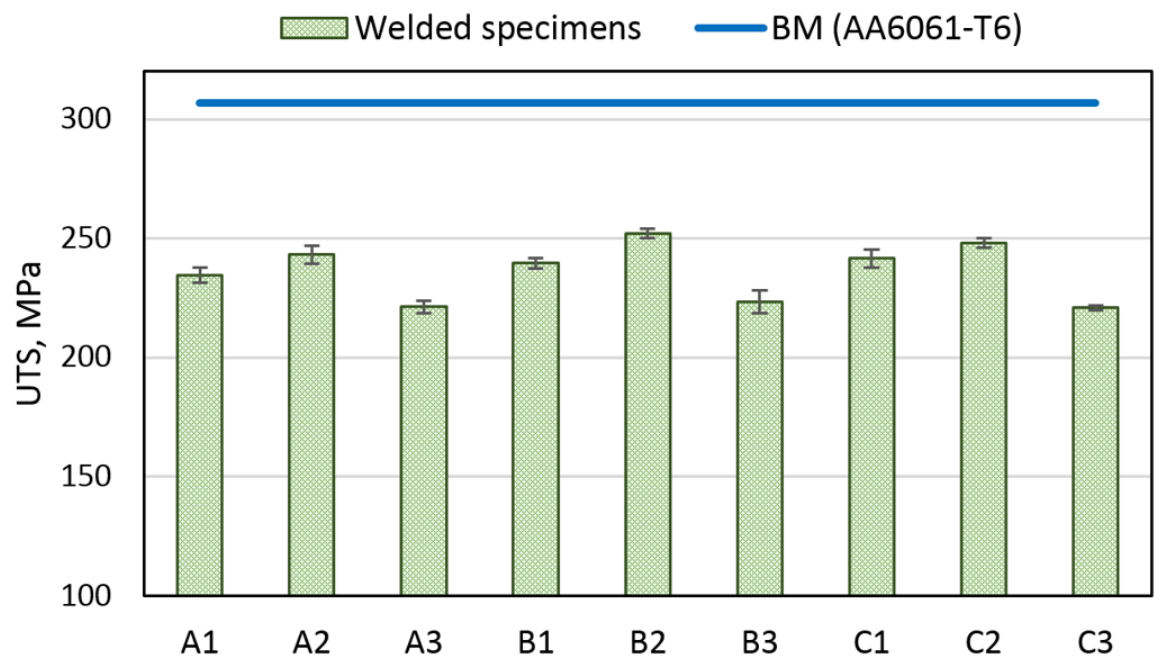

Figure 5. Ultimate tensile strength of the welded joints. 
On a centerline normal to the welding direction across the nugget, Figure 6 shows the Vickers micro-hardness profiles of specimens B2 and C3, which exhibited the highest and lowest tensile strength, respectively. Compared to the base materials, it is clear from the two line graphs that the Vickers hardness number (VHN) fluctuated with a slight gradient in the nugget region and a noticeable drop in the HAZ of both alloys. The biggest drop was at the HAZ of the AA6061 alloy in the AS, where the hardness fell to the lowest values of 71 for specimen B2 and 66 for specimen $\mathrm{C} 3$ at about $5 \mathrm{~mm}$ away from the weld centerline. This decline clarifies the reason behind the location of failure in the tensiletests, as seen in the sample specimen surrounded by the red ellipse. Other than that, it has been reported that the change in material properties at the HAZ resulted from the sufficient heating during the welding process [4]. On the other side, the maximum tensile residual stresses commonly concentrated in the thermo-mechanical, affecting zone (TMAZ) and/or HAZ [49]. However, the use of aluminum, which has a high thermal diffusivity, as a backing plate and cover bar over the steel anvil and below the steel pressure bar contributes an increase in the cooling rate and hence reduces the alteration in the mechanical properties [50]. Similarly, the side L-shaped plates also assisted, as an additional heat sink, to extract more amount of heat and control the temperature distribution. The average nugget hardness was lower compared to the base materials with a slight decrease in the AA6061-nugget related to the AA7075-nugget side. The best weldment with smooth surface finish, gap and defects free and good materials mixing were produced by the (B2) conditions, as shown in Figure 7.

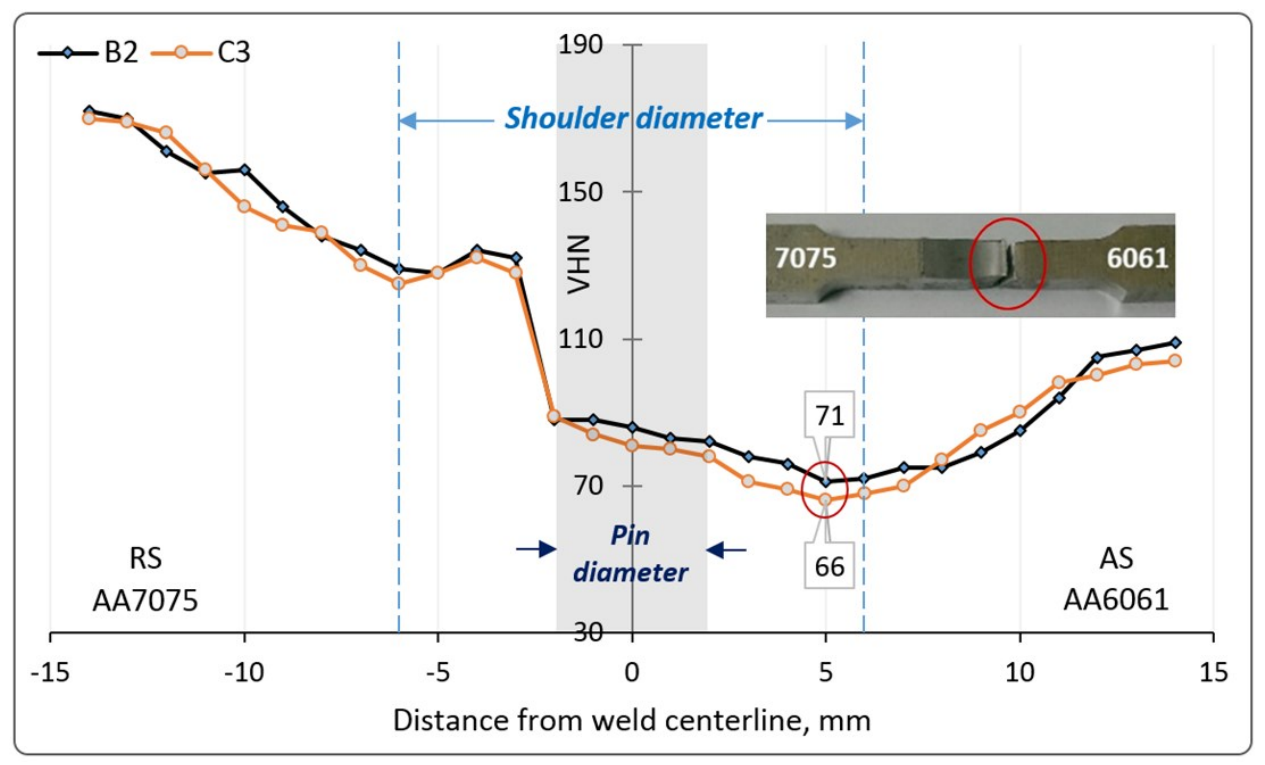

Figure 6. Vickers micro-hardness distributions of specimens B2 and C3.

It is clear from the micrographs that the dynamic recrystallization caused in fine and equiaxed grains inside the nugget zone. The TMAZ and the HAZ are close to the nugget and quite similar in grain size to those of BM in both sides, because of the higherdiffusivity backing and clamping materials and the subjected lateral pressure. Furthermore, the heat flux generated throughout the joining process is not enough to recrystallize the grains at the TMAZ, as has been reported by Cavaliere et al. [51, 52]. However, the direction of grains is slightly rotated duo to the vertical material flow [48]. This transportation of material from the shoulder down to the bottom of the pin is caused by the tool pin threads, which have been fabricated in a direction opposite to that of the 
tool rotation [8]. Onion rings are also noticed at the nugget area, which has been improved by the additional flat on the probe's cone [47]. Moreover, the etching response of the two alloys to the Keller's reagent is not the same due to the differences in chemical composition between the base materials [53]. For this reason, the micrographs appear in dark and light colors. It is worth noting herein to mention that promising results are gained by the use of the present simplified system of clamping and fixtures in comparison with the few published data. Relatively high tensile strength of the welded joints and very good quality are clearly observed from the results of this work.

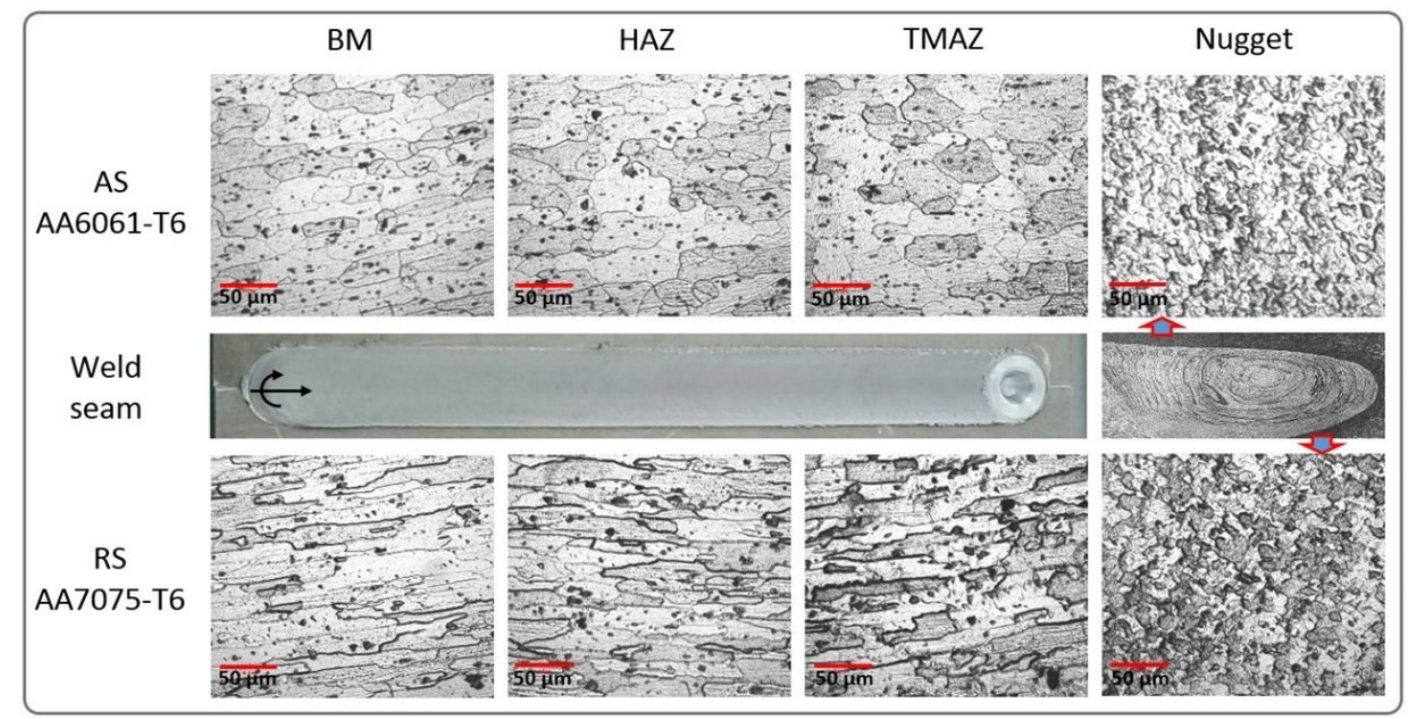

Figure 7. Macro and microstructure with the weld seam of the (B2) specimen.

\section{CONCLUSIONS}

Results of the present work show that the present simplified design can effectively be used to achieve sound welds with smooth surface finish, gap and defects free and without geometric imperfections. All of the test coupons of AA7075 and AA6061 aluminum alloys used to examine the validity of the clamping system exhibited relatively high tensile strength. The UTS of joints ranged from $220.9 \mathrm{MPa}$ when the rotation and welding speeds were $1200 \mathrm{rpm}$ and $350 \mathrm{~mm} / \mathrm{min}$, respectively to the maximum value of 252.1 MPa when the rotation speed fixed at $1100 \mathrm{rpm}$ and the welding speed at $300 \mathrm{~mm} / \mathrm{min}$. With this reason, the maximum value of the UTS represents an efficiency of about $82 \%$ with respect to the UTS of the AA6061 alloy. This efficiency is higher than the acceptable limit due to the standards of the American Welding Society (AWS). Thus, the best test shows a minimum Vickers hardness number of about 71 at the HAZ of the AA6061 alloy, where the failure in the tensile test occurred. For future research directions, it is recommended to improve the present test-rig for further investigations. While it is specially designed for butt-joint FSW research, it can be used as a clamping/backing system for lap-joint configuration.

\section{ACKNOWLEDGEMENTS}

The authors would like to be obliged to the Malaysian Ministry of Education for providing research FRGS grant (RDU130112), followed by a special thanks to Universiti Malaysia 
Pahang for laboratory facilities. A special appreciation from the first author to the University of Technology and the Ministry of Higher Education of Iraq.

\section{REFERENCES}

[1] Parida B, Vishwakarma SD, Pal S. Design and development of fixture and force measuring system for friction stir welding process using strain gauges. Journal of Mechanical Science and Technology. 2015;29:739-49.

[2] Upadhyay P, Reynolds AP. Effects of forge axis force and backing plate thermal diffusivity on FSW of AA6056. Materials Science and Engineering: A. 2012;558:394-402.

[3] Imam M, Racherla V, Biswas K. Effect of backing plate material in friction stir butt and lap welding of 6063-T4 aluminium alloy. International Journal of Advanced Manufacturing Technology. 2015;77(9):2181-95.

[4] Colligan KJ. The friction stir welding process: an overview. In: Lohwasser D, Chen Z, editors. Friction Stir Welding: Woodhead Publishing; 2010. p. 15-41.

[5] Zappia T, Smith C, Colligan K, Ostersehlte H, Kallee SW. 4 - Friction stir welding equipment. In: Lohwasser D, Chen Z, editors. Friction Stir Welding: Woodhead Publishing; 2010. p. 73-117.

[6] Sathari NAA, Shah LH, Razali AR. Investigation of Single-Pass/Double-Pass Techniques on Friction Stir Welding of Aluminium. Journal of Mechanical Engineering and Sciences. 2014;7:1053-61.

[7] Abd Razak NA, Ng SS. Investigation of Effects of MIG Welding on Corrosion Behaviour of AISI 1010 Carbon Steel. Journal of Mechanical Engineering and Sciences. 2014;7:1168-78.

[8] Mishra RS, Mahoney MW. Friction stir welding and processing: ASM International; 2007.

[9] Smith CB, Hinrichs JF, Crusan WA, Leverett J. FSW Stirs Up Welding Process Competition. Forming and Fabricating. 2003:25-31.

[10] Zain-Ul-Abdein M, Nélias D, Jullien JF, Deloison D. Thermo-mechanical analysis of laser beam welding of thin plate with complex boundary conditions. International Journal of Material Forming. 2008;1:1063-6.

[11] Liu C, Zhang JX. Numerical simulation of transient welding angular distortion with external restraints. Science and Technology of Welding and Joining. 2009;14:26-31.

[12] Liu QS, Mahdavian SM, Aswin D, Ding S. Experimental study of temperature and clamping force during Nd:YAG laser butt welding. Optics \& Laser Technology. 2009;41:794-9.

[13] Zain-ul-abdein M, Nélias D, Jullien J-F, Deloison D. Experimental investigation and finite element simulation of laser beam welding induced residual stresses and distortions in thin sheets of AA 6056-T4. Materials Science and Engineering: A. 2010;527:3025-39.

[14] Sathari NAA, Razali AR, Ishak M, Shah LH. Mechanical Strength of Dissimilar Aa7075 and Aa6061 Aluminum Alloys Using Friction Stir Welding. International Journal of Automotive and Mechanical Engineering. 2015;11:2713-21.

[15] Ishak M, Noordin NFM, Razali ASK, Shah LHA, Romlay FRM. Effect of filler on weld metal structure of AA6061 aluminum alloy by tungsten inert gas welding. International Journal of Automotive and Mechanical Engineering. 2015;11:243846. 
[16] Ahmad R, Asmael MBA. Effect of aging time on microstructure and mechanical properties of AA6061 friction stir welding joints. International Journal of Automotive and Mechanical Engineering. 2015;11:2364-72.

[17] Christner B, Sylva G. Friction stir welding development for aerospace applications. ICAWT. Columbus, OH, USA.1996, p. 359-68.

[18] Leonard A, Lockyer S. Flaws in friction stir welds. 4th International Symposium on Friction Stir Welding: Park City, Utah, USA; 2003.

[19] Richter-Trummer V, Suzano E, Beltrão M, Roos A, dos Santos JF, de Castro PMST. Influence of the FSW clamping force on the final distortion and residual stress field. Materials Science and Engineering: A. 2012;538:81-8.

[20] Fratini L, Micari F, Buffa G, Ruisi VF. A new fixture for FSW processes of titanium alloys. CIRP Annals - Manufacturing Technology. 2010;59:271-4.

[21] Upadhyay P, Reynolds A. Effect of Backing Plate Thermal Property on Friction Stir Welding of 25-mm-Thick AA6061. Metallurgical and Materials Transactions A. 2014;45:2091-100.

[22] Khodir SA, Shibayanagi T, Naka M. Control of hardness distribution in friction stir welded AA2024-T3 aluminum alloy. Materials Transactions. 2006;47:15607.

[23] Hatifi MM, Firdaus MH, Razlan AY. Modal Analysis of Dissimilar Plate Metal Joining with Different Thicknesses using MIG Welding. International Journal of Automotive and Mechanical Engineering. 2014;9:1723-33.

[24] Hariri A, Azreen P N, Abdull N, Leman AM, Yusof MZM. Determination of customer requirement for welding fumes index development in automotive industries by using quality function deployment approach. International Journal of Automotive and Mechanical Engineering. 2014;9:1609-19.

[25] Chaki S, Ghosal S. A GA-ANN hybrid model for prediction and optimization of $\mathrm{CO}_{2}$ laser-mig hybrid welding process. International Journal of Automotive and Mechanical Engineering. 2015;11:2458-70.

[26] Murphy A, Ekmekyapar T, Quinn D, Özakça M, Poston K, Moore G, et al. The influence of assembly friction stir weld location on wing panel static strength. Thin-Walled Structures. 2014;76:56-64.

[27] Mishra RS, De PS, Kumar N. FSW of aluminum alloys. Friction stir welding and processing: Springer; 2014. p. 109-48.

[28] Charde N. Effects of electrode deformation of resistance spot welding on 304 austenitic stainless steel weld geometry. Journal of Mechanical Engineering and Sciences. 2012;3:261-70.

[29] Dursun T, Soutis C. Recent developments in advanced aircraft aluminium alloys. Materials \& Design. 2014;56:862-71.

[30] Bayazid SM, Farhangi H, Asgharzadeh H, Radan L, Ghahramani A, Mirhaji A. Effect of cyclic solution treatment on microstructure and mechanical properties of friction stir welded 7075 Al alloy. Materials Science and Engineering: A. 2016;649:293-300.

[31] Abd Razak NA, Ng SS. Investigation of effects of MIG welding on corrosion behaviour of AISI 1010 carbon steel. Journal of Mechanical Engineering and Sciences. 2014;7:1168-78.

[32] Shah L, Akhtar Z, Ishak M. Investigation of aluminum-stainless steel dissimilar weld quality using different filler metals. International Journal of Automotive and Mechanical Engineering. 2013;8:1121-31. 
[33] Kumar N, Mishra RS, Yuan W. Friction Stir welding of dissimilar alloys and materials: A Volume in the Friction Stir Welding and Processing Book Series: Butterworth-Heinemann; 2015.

[34] Çam G, Mistikoglu S. Recent developments in friction stir welding of Al-alloys. Journal of Materials Engineering and Performance. 2014;23:1936-53.

[35] NAA S, AR R. Investigation of single-pass double-pass techniques on friction stir welding of aluminium. Journal of Mechanical Engineering and Sciences. 2014;7:1053-61.

[36] Fu MJ, Li XH, Han XQ, Xu HY. Research on work hardening type superplastic deformation behavior of FSW titanium alloy. Materials Science Forum, 2016; 838-839; 506-11.

[37] El-Batahgy A-M, Miura T, Ueji R, Fujii H. Investigation into feasibility of FSW process for welding $1600 \mathrm{MPa}$ quenched and tempered steel. Materials Science and Engineering: A. 2016;651:904-13.

[38] Gao Y, Nakata K, Nagatsuka K, Matsuyama T, Shibata Y, Amano M. Microstructures and mechanical properties of friction stir welded brass/steel dissimilar lap joints at various welding speeds. Materials and Design. 2016;90:1018-25.

[39] Murr LE. A Review of FSW Research on dissimilar metal and alloy systems. Journal of Materials Engineering and Performance. 2010;19:1071-89.

[40] Guo JF, Chen HC, Sun CN, Bi G, Sun Z, Wei J. Friction stir welding of dissimilar materials between AA6061 and AA7075 Al alloys effects of process parameters. Materials \& Design. 2014;56:185-92.

[41] İpekoğlu G, Çam G. Effects of initial temper condition and postweld heat treatment on the properties of dissimilar friction-stir-welded joints between AA7075 and AA6061 aluminum alloys. Metallurgical and Materials Transactions A. 2014;45:3074-87.

[42] Cole EG, Fehrenbacher A, Duffie NA, Zinn MR, Pfefferkorn FE, Ferrier NJ. Weld temperature effects during friction stir welding of dissimilar aluminum alloys 6061-t6 and 7075-t6. International Journal of Advanced Manufacturing Technology. 2013;71:643-52.

[43] Shah LH, Zainal Ariffin NF, Razali AR. Parameter optimization of AA6061AA7075 dissimilar friction stir welding using the Taguchi method. Applied Mechanics and Materials. 2014;695:20-3.

[44] Ishak M, Shah LH, Aisha ISR, Hafizi W, Islam MR. Study of resistance spot welding between AISI 301 stainless steel and AISI 1020 carbon steel dissimilar alloys. Journal of Mechanical Engineering and Sciences. 2014;6:793-806.

[45] Metals ASf, Davis JR. ASM handbook. 2. Properties and selection: nonferrous alloys and special-purpose materials: ASM international; 2009.

[46] Rai R, De A, Bhadeshia HKDH, DebRoy T. Review: friction stir welding tools. Science and Technology of Welding and Joining. 2011;16:325-42.

[47] Thomas W, Norris I, Staines D, Watts E. Friction stir welding-process developments and variant techniques. The SME Summit. 2005;1:1-21.

[48] Peel M, Steuwer A, Preuss M, Withers PJ. Microstructure, mechanical properties and residual stresses as a function of welding speed in aluminium AA5083 friction stir welds. Acta Materialia. 2003;51:4791-801.

[49] Williams SW, Steuwer A. 8 - Residual stresses in friction stir welding. In: Lohwasser D, Chen Z, editors. Friction Stir Welding: Woodhead Publishing; 2010. p. 215-44. 
[50] Zettler R. 3 - Material deformation and joint formation in friction stir welding. In: Lohwasser D, Chen Z, editors. Friction Stir Welding: Woodhead Publishing; 2010. p. 42-72.

[51] Cavaliere P, Nobile R, Panella FW, Squillace A. Mechanical and microstructural behaviour of 2024-7075 aluminium alloy sheets joined by friction stir welding. International Journal of Machine Tools and Manufacture. 2006;46:588-94.

[52] Cavaliere P, Cerri E, Squillace A. Mechanical response of 2024-7075 aluminium alloys joined by Friction Stir Welding. Journal of Materials Science. 2005;40:3669-76.

[53] Firouzdor V, Kou S. Formation of liquid and intermetallics in Al-to-Mg friction stir welding. Metallurgical and Materials Transactions A. 2010;41:3238-51. 